\title{
Selected Reference Works, 2004
}

\section{Sarah Witte and Mary Cargill}

\begin{abstract}
This article follows the pattern set by the semiannual series initiated by the late Constance $\mathrm{M}$. Winchell more than fifty years ago and continued first by Eugene Sheehy and then by Eileen Mcllvaine. Because the purpose of the list is to present a selection of recent scholarly and general works, it does not pretend to be either well balanced or comprehensive. A brief roundup of new editions of standard works is provided at the end of the articles. Code numbers (such as AC527) have been used to refer to titles in the Guide to Reference Books, $11^{\text {th }}$ ed. (Chicago: ALA, 1996).
\end{abstract}

\section{Bibliography}

Editoria Italiana Online (EIO): Italian Research Publications Online [electronic resource]. Fiesole: Casalini Libri, Digital Division (http://eio.casalini.it/). Subscription price varies. ISSN 1724-1634. Editoria Italiana Online is the first fulltext Italian-language database of current monographs and journals. It includes some 100 journal titles, 100 conference proceedings, and 500 monographs from eighteen publishers of scholarly works in Italy. Among the participating publishers are the University Presses of Pisa and Florence, Leo S. Olschki, Longo, Cadmo, Istituti Editoriali e Poligrafici Internazionali, and the École Française de Rome. These sources cover a variety of subject fields from earth science to poetry with the emphasis on the humanities and social sciences. This is a growing database to which new materials will be added throughout the year.
Searching is straightforward. Boolean, proximity, phrase, and wild card search commands can be used in full-text keyword search, in addition to searching by author, title, or publisher. It is possible to limit a search to a type of publication or a specific publisher's catalog. Texts in PDF format can be printed or copied and pasted, although there is a fee for downloading the entire text of a monograph. EIO supplies electronic catalog records for items in the database, so books or journals in the database can be accessed directly from the library catalog. A CD$\mathrm{ROM}$ of periodical data is supplied for archival purposes at the end of the year upon request.

Scholars in the field of Italian studies will be delighted by the convenience of consulting journals and books from their home computers and by the quality of publications in the collection. We have a number of non-English bibliographic

Sarah Witte and Mary Cargill are reference librarians in Butler Library at Columbia University; e-mail: spurgin@columbia.edu and cargill@columbia.edu. Although it appears under a byline, this list is a project of the reference departments of Columbia University Libraries and notes are signed with the initials of one of the following staff members: Barbara Sykes-Austin, Avery Library; Anice Mills, Jean Laponce, Robert H. Scott, Junko Stuveras, Butler Library; James L. Coen and Kathleen Dreyer, Business and Economics Library; and Fadi H. Dagher, Lehman Social Sciences Library. 
databases, foreign national library catalogs online, and "past master-types" of collections of texts such as ARTFL, the University of Sardinia online collection of Italian authors, and the Letteratura Italiana Zanichelli (CD-ROM), but there is nothing comparable to this collection of contemporary scholarship from reputable publishers. In the future, it may evolve into an innovative way of disseminating scholarly works.

Recommended for large research libraries serving Italian-speaking readers and consortia of academic libraries. For more information, visit the EIO Web site at http://eio.casalini.it/. The list of periodicals and books is available there.-J.S.

\section{Dictionaries}

\section{Montgomery, Michael B., and Joseph}

S. Hall. Dictionary of Smoky Mountain English. Knoxville: Univ. of Tennessee Pr., 2004. 792p. illus. \$75 (ISBN: 157233-222-0). LC 2003-012372.

Based on research begun in 1937 by linguist Joseph Sargent Hall and supplemented by work done more recently by Michael Montgomery, this dictionary is a comprehensive historical record of the regional speech of the Smoky Mountains of East Tennessee and Western North Carolina. Gathered from Hall's meticulous field notebooks, oral speech recorded on aluminum and acetate discs in the late 1930s, written sources dating back to 1784, early church minutes, Civil War letters, and written commentaries, the dictionary features more than six thousand names, usages, meanings, and folk expressions and more than fifteen thousand documented quotations. As a result, it also offers a realistic portrayal of the culture, social mores, and customs of this distinctive region. Terminology for herbal medicine, moonshining, cooking, music, religious customs, logging, and farming provide an accurate historical view of Smokies speech and lifestyle. For someone unfamiliar with regional English, this dictionary will reveal words and phrases as if in a foreign language. Not only did I learn there are at least twenty-nine words relating to bears, but that if I want to learn them all, I'd need "bear dog grit," or tenacity.

Entries are arranged following the principles of the Oxford English Dictionary (AC33) and the Dictionary of American Regional English (AC151). Each entry has three main divisions: opening section or headword; definition; and body of supporting citations. Terms judged to be colloquial usage or slang have been excluded. A User's Guide and a section on grammar and syntax are particularly helpful. The dictionary concludes with a chronological list of works cited ranging from 1784 to 2002. Full-color maps of the Smoky Mountain region on the inside covers show the 1939 place-names from the dictionary citations and give some context to the specific area of study. This thorough, authoritative work will be of immense value to linguists, historians, and folklorists alike. And Roy Blount Jr.'s humorous and glowing review in the New York Times Book Review (11/21/04) may make this reference book one that is highly recommended for scholars, yet appeals to a general audience as well. - A. M.

\section{Biography}

\section{Oxford Dictionary of National Biog-}

raphy [electronic resource]. Oxford: Oxford Univ. Pr., 2004- (http://www. oup.com/oxforddnb/info/). illus. Subscription price varies.

The Oxford Dictionary of National Biography, recently issued in a new print edition, has also appeared online this year. It offers the same access as the print to the biographies of some 50,000 individuals by approximately 10,000 contributors, comprising 62 million words and 10,000 
illustrations. However, the powerful new kind of access provided by this online format justifies its treatment here as a separate publication. Indeed, it is certainly one of the most important scholarly electronic offerings of the past year. (The earlier edition of the DNB also had an electronic equivalent, but its limitation to a CD-ROM format and quite different interface likewise justify the treatment of the online ODNB as a new publication.)

Users are provided with a rich, but well-organized, array of options for searching and exploring its contents. Two quick-search boxes allow users to look up individuals by name (with automatic cross-referencing for variant forms) or to look for specific words or phrases anywhere in the article text. These are supplemented by five advanced searches, enabling more fine-tuned searching to produce very specific results:

The advanced People Search allows users to look in combination for any part of a name (including personal names and titles), to limit results to a specific "field of interest" (meaning the field or occupation in which the individual was chiefly active or from which he or she derived fame) chosen from an expandable list, to limit by gender or to articles relating to families, to specify (in more general and specific ways) the dates of an individual's life or activity, to search by religious affiliation, to restrict results to articles including images, and to further qualify the search with some words or phrase in the full text. Any combination of the preceding fields is also possible.

The advanced Full-Text Search enables users to construct three-term Boolean searches of the whole text or designated parts thereof, including searches of the references (which are not, thankfully, included in the full-text search). One regrets the apparent absence of a proximity search, an important (but frequently omitted) feature of the ideal full-text search engine, even though the relatively narrow size and focused character of the articles probably rule out too many false hits where proximity could be important. (There actually was a proximity search in the old CD-ROM version of the DNB.) The wild card feature also is a bit unintuitive: the reader must be sure to have unchecked the "exact" button before it will work, even though no error message is displayed if one includes a wild card character but neglects to disenable the "exact" setting. Even so, the editors deserve high marks for providing an empowering, straightforward search in which the searcher sets the terms of the query, as opposed to some other outstanding online encyclopedias that offer a murky range of choices in which only the programmer ultimately knows for sure what is being retrieved and why.

The advanced References Search offers an exploration of the solid apparatus accompanying each article, enabling searches of various features of the items in the bibliography ("Sources") and of references to archival holdings, portraits, and, fascinatingly enough, the wealth of the individual at the time of his or her death. The advanced Contributors Search enables users to find articles written by a particular author (some of whom were themselves quite distinguished persons) by name or initials. Finally, the advanced Images Search supports retrieval of all the works by a given artist, created within a given range of years, or held in a given locale or repository (but not a search for the portrait of a given individual because this can be obtained more readily as part of the Persons search).

Finally, the dictionary offers the reader less certain of his or her ultimate destination a variety of very interesting options for browsing. One may survey the contents by name, by author of article, 
by a growing list of thematic groups, or even by the frivolous "get a life" feature, which pulls up an entry at random. One may likewise browse chronologically by actual (or estimated) date of birth or death. Additional rewards available after one has reached the article itself include significant online links (say, to an archival finding aid) as well as links to the DNB archive, where an earlier version of the article exists. And when a list of results has been obtained by searching, it may be further refined by sorting or applying various limits.

The benefits for researchers, students, and those generally interested in the history and culture of the English-speaking world are manifest. Through full-text searching, users can retrieve at a moment, say, all the biographies of members of the Bloomsbury Group or associates of Virginia, or a collection of articles on individuals associated with the Scottish covenanting movement, or temperance activists of the early nineteenth century, or persons involved in the study and exploration of, or relations with, Ethiopia, or virtually any other related group of individuals. Or users can survey the individuals prominent in a particular field or locality or assemble a group of their portraits. The work is not only a powerful reference, but also a pleasantly browsable source, whose many search features and hyperlinks encourage further exploration.

It is hard to imagine any library with online resources documenting English history, literature, language, or culture not wanting to acquire this work. Its breadth, depth, and flexibility make it very much the peer of its distinguished Oxford cousin, the OED online. - R.H.S.

\section{Religion}

The Encyclopedia of Protestantism. Ed. Hans J. Hillerbrand. New York: Rout- ledge, 2004. 4 vols. illus. \$495 (ISBN

0-415-92472-3). LC 2003-011582.

This is an attempt to cover, from broad chronological and geographical perspectives, everything Protestant. Topics from doctrinal issues to poetry and music are treated in four volumes (each volume has approximately 550 pages). The same editor who offered the Oxford Encyclopedia of the Reformation (New York, 1996) now brings the story up to date, examining the development of myriad shades of Protestantism in the world since the sixteenth century.

An alphabetical list of topics is followed by a thematic list, which is indicative of the scope of the encyclopedia. The largest segment consists of biographical entries that include historically significant persons from Martin Luther to Billy Graham. The headings "Creeds, Confessions, and Religious Works," "Theological," "Traditions and Faith Groups," and "Movements" bring together entries on various denominations and movements. "Culture and Social Issues" entries cover not only "Bible and Literature," but also topics such as gender, marriage, masculinity, homosexuality, and ethnicity.

The bibliographies at the end of each article typically give six to twelve references. Some bibliographies are divided into primary and secondary sources. Longer articles are divided into segments with captions making the encyclopedia easier to use. All the articles are signed, and the list of contributors (with affiliation and article contributed) follows the appendix in Vol. 4. The appendix also includes five statistical tables of adherents by denomination and country. The index is easy to use and helpful, although there are occasionally puzzling entries. An example is Elizabeth I of England. She is listed twice, once as "Elizabeth I, Queen of England" and then as "Elizabeth I (Elizabeth Tudor)." Her main biography is 
under the second heading along with four other references, and the first heading has eleven more references. The encyclopedia has consecutive page numbering, and the index gives page reference only, but a convenient volume key is found on every page of the index. Page numbers of main entries are printed in bold to help readers locate the essential source quickly.

Recommended for college and research libraries. -J. S.

\section{Encyclopedia of Religion and War. Ed.}

Gabriel Palmer-Fernandez. New York: Routledge, 2004.530p. illus. \$125(ISBN 0-415094246-2). LC 2003-012412.

The ideal of the separation of church and state is a tenet of Western Europe and was embodied in the early twentiethcentury laws that removed education as well as the institution of marriage from the control of the church. In the twentyfirst century, however, many shades of religions have once again emerged as formidable political forces. The editors of the Encyclopedia assert that by the end of the twentieth century, the theories of gradual secularization of public life were proven wrong by the phenomena of Christian fundamentalism in American politics as well as by the founding of an Islamic republic in Iran. In today's world, where both authoritarian and democratic regimes are plagued by religiously motivated violence from Ireland to Chechnya, it is timely to have a reference work that looks back and examines the history of "religiously motivated violence" in the context of extremely varied geographic and religious backgrounds. The editors identify and emphasize "three salient themes" in the connection between religion and violence: (1) existence of "explicitly scriptural and doctrinal views on war" in most religion; (2) religions' support of states in wars; and (3) wide representation of pacifism and nonvio- lence among religions (Introd.).

The encyclopedia covers the period from Zoroastrianism (1500 BC) to the contemporary Taliban and discusses practically every significant religious denomination or sect from Daoism to Wahhabism. Although the scope is worldwide and timeless, the editors state that the book has "a narrow focus" and examines almost exclusively "the dark alliance between religion and violence (p. xii)." One significant feature of this encyclopedia is that it acknowledges the fact that religions experience change and internal diversity over time, so Hinduism and Judaism are examined by historical time periods and the branches of Buddhism, Islam, and Christianity are each addressed by separate articles.

Each article or section of an article is accompanied by a bibliography for further reading that typically lists eight to twenty titles. Black-and-white photographs and texts of relevant documents such as the Edict of Nantes (1598) and the Constitution of Saudi Arabia (1992) provide helpful illustrations. The book has a list of contributors (pp. 479-83) and a good index (pp. 485-530). Recommended for all types of libraries. - J.S.

\section{Art and Architecture}

Atlas of World Art. Ed. John Onians.

London: Laurence King Pub., 2004.

352p. illus. \$150 (ISBN 1-85669-377-5).

LC 2004-426470.

After leafing through, and thoroughly enjoying, the Atlas of World Art, this reviewer would have to agree with its editor, John Onians, when he writes in his introduction that " $t$ t]here has probably never been an art book of such potential interest to so many people" (p.10). This is an exciting book in many ways, not least in that the simple, elegant, and clear presentation of the visual and textual material makes one want to know more about every subject 
covered. This is certainly possible with the bibliography provided after the final chapter and before the general index. It also is due to the equal coverage given to time and place that illuminates context and opens as many doors as there are chapters in this book on human artistic creativity of the past 40,000 years.

Thematically and chronologically arranged, these are: Part I: "Art, Hunting and Gathering 40,000-5,000 BC"; Part II: "Art, Agriculture and Urbanization 5,000-500 BC"; Part III: "Art, War and Empire 500 BC-AD 600"; Part IV: "Art, Religion and the Ruler 600-1500"; Part V: "Art, Exploitation and Display 1500-1800"; Part VI: "Art, Industry and Science 1800-1900"; Part VII: "Art, Ideas and Technology 1900-2000." Geographical divisions multiply from simply the world in part I to continental and regional subdivisions that form the separate chapters of parts II through VII. Each of these chapters is allotted two pages, with two or three maps and two illustrations of works of art; often one two-dimensional work such as a painting, drawing, or print; and one three-dimensional work that might include a piece of sculpture or a textile, a building, or an archaeological site.

What is so striking about the maps and their legends and the careful choice of artworks is how clearly they record the activities and migrations of peoples, how humans have organized themselves geographically, culturally, and politically over time, and the art and artifacts that remain to represent their lives. The emphasis in the organization of this volume is on the interactions of people with nature across time and space and the "art-making" that has resulted from this human geography and ecology (Ibid.).

Sixty-eight contributors have written the essays for each chapter, with introductions to the volume and each of the seven parts by Onians. His closing para- graph in the main introduction hit on this reviewer's own experience with this book: "Those who take advantage of all the opportunities the Atlas offers will acquire an unprecedented understanding of art as a worldwide human behaviour. They will also acquire a much-needed awareness of our ignorance about it" (p.13). Hence the excitement in discovering that this is a book that can begin to connect the dots.-B.S.-A.

\section{Phaidon Atlas of Contemporary World}

Architecture. Comprehensive ed. London: Phaidon, 2004. 812p. illus. \$160 (ISBN 0-7148-4312-1).

Despite the media blitz of full-page ads in art and architecture magazines, and the dutiful preparations by librarians (as evidenced in certain discussion lists) to provide it with suitable display shelving, this hefty volume is not really a reference book of importance at all. If anything, it is a sore thumb of a book wanting to be taken seriously as the last word on the current state of contemporary architecture worldwide. But only its size, at 16 and three-quarters inches by 21 and-aquarter inches by 4 inches, and a weight of over 16 and a half pounds, makes it noteworthy.

However, the Phaidon Atlas is being acquired by nearly every library with an architecture collection. Its claim to be a "comprehensive portrayal of the best contemporary architecture from around the world" (Foreword) deserves consideration. Eleven-hundred buildings completed between 1998 and 2002 were selected by an editorial panel that, remarkably, is not identified anywhere in the volume. It has come to this reviewer's attention that this "inexplicable" omission was overlooked in the final proofs (see McLeod, Virginia. "Atlas Response." Architectural Review Sept. 2004, p.44), leading one to question the quality of 
editorial attention elsewhere in the volume as well.

The organization is appropriately geographical, generally by continent, with color-coded pages that match the layout in the table of contents. The selection of built works, however, clearly eschews any stylistic choice based on regional characteristics. These are all contemporary buildings in form and style. They are illustrated with photographs, plans, and drawings supplied by the architects themselves or independent photographers not commissioned by the Atlas editors (Ibid.) The layout, and the choice of photographs, their size, and the rendering of detail, therefore, relied more on what was conveniently at hand rather than on a cohesive design concept for the entire volume.

Another shortcut appears in the maps, which pinpoint the location of featured buildings by number only, unless they are in a major city, in which case the city alone is identified. A dot with a number on a map of, say, the Australian bush is no indication of what type of building one will find there. The reader must be interested in contemporary Australian architecture generally and therefore curious to see what this isolated example might be. This is true for every country covered. The frontmatter, customary in atlases, of presenting statistical data here provides tables on population and urbanization trends, and "economy, environmental sustainability, human development indicators and architecture," a mixed bag, certainly. This last gives the number of registered architects, architecture schools, and students enrolled in them. The final pages are devoted to a table of building types represented, an index by building name, and an index of architects.

Regular readers of the architectural periodical literature will see very little with which they are not already familiar, suggesting that this atlas might best be used by novices in the field-perusers in the public library, high school and college undergraduates, perhaps-or in academic collections with such straightened budgets that some of the best glossy magazines cannot be included in their subscription lists. - B.S.-A.

\section{History and Area Studies}

Encyclopedia of Russian history. Ed. James R. Millar. New York: Macmillan Reference USA, 2004. 4 vols. illus. \$475 (ISBN 0028656938). LC 2003-14389.

For some time, the standard Englishlanguage encyclopedia for Russian history has been the Modern Encyclopedia of Russian, Soviet and Eurasian History (Gulf Breeze, Fla.: Academic International Press, 1976-) whose original set was completed in 1993, but which has been continued with a set of supplementary volumes since 1995 . That work has been a valuable tool for acquainting Englishlanguage readers with a wide range of issues, but its large size and great detail, frequent reference to Russian or other non-English bibliography, heavy reliance on Soviet sources, and multiple alphabetical series, combined with the now rather early date of many of its volumes and the slow rate of appearance of the supplementary volumes, has left room for an accessible, comprehensive, and authoritative work for nonspecialists. The need has been particularly great given the sweeping changes that have taken place in Russia in the past two decades. Some basic one-volume handbooks have been available, but these can only provide a certain amount of detail.

Hence, the appearance of this new work, edited by Ronald Millar of George Washington and a distinguished board, and written by a team of more than 450 scholars, most of them from U.S. colleges and universities, but with some represen- 
tation of Russian and other international institutions abroad. The authors include many of the leading voices in Russian historiography today, such as Richard Hellie, Ronald Suny, Sheila Fitzpatrick, Simon Franklin, Nancy Shields Kollman, Gregory Freeze, and Patricia Grimsted, to name but a few. The essays, written with the aim of providing authoritative information to the nonspecialist, range from three or four paragraphs to a few pages in length, providing information on a range of topics: agriculture, economics, education, foreign relations, government, historical events, journalism, law and the judiciary, military affairs, political organizations and policy, regions, nations, nationalities, religion, and rulers, political leaders and other historical figures, and a wealth of other topics. Some key selected coverage also is provided of the arts, literature, and culture. Perhaps the work might have benefited from a slightly more systematic coverage of social issues, and, given its importance, perhaps more could have been said about Soviet science and technology, but these are minor points: overall, the work does an excellent job of covering the key questions. Each article ends with a list of some of the key Englishlanguage literature on the field, providing a good starting point for further research. Those wishing to browse the contents can take advantage of three listings (alphabetic, thematic, and by contributor). An index at the end provides access to the contents, although it could, frankly, have been given a little more attention: references to page numbers rather than volumes is a cumbersome approach in a multivolume work, and subject terms are not as well collocated as they might have been (e.g., the article "Dvorianstvo" is noted by a separate index entry under that term but is not listed under the heading for "nobility," and "First Lithuanian Statute of 1529," "Lithuanian Statute," and
"Third Lithuanian Statue in 1588" are independent headings in the index pointing to separate pieces of text in different parts of the work. A minor point, perhaps, but something a reference publisher ought to be keeping in mind.

That point notwithstanding, this is an important new addition to the reference literature. Fittingly, it was included in American Libraries' "Top 20 Reference Titles of the Year" (May 2004 issue). It clearly belongs in any reference collection aiming to provide coverage of Russian history and culture. Designed with the nonspecialist in mind, students and researchers working in the Russian field also will no doubt find it a handy reference as well. - R.H.S.

\section{Lengel, Edward G. World War I Memories:} An Annotated Bibliography of Personal Accounts Published in English since 1919. Lanham, Md.: Scarecrow, 2004. 311p. $\$ 50$ (ISBN 0-9108-5008-7). LC 2004003334.

The compiler, the associate editor of the Papers of George Washington project at the University of Virginia and an associate professor of history, has scoured the literature of World War I, and this bibliography should be extremely useful for any library whose students need primary sources. He has included "any firsthand account or reminiscence of an author's experience in the First World War" (Pref.), including autobiographies, memoirs, diaries, and letters published after 1919; political memoirs, literary essays, anthologies, unit histories, fictional accounts, and journal articles are excluded, as are unpublished manuscripts. All of the belligerent countries are included, though the vast majority are from English-speaking areas. For accounts published during the war, he refers the reader to Loleta Dawson's 1921 European War Fiction in English, and Personal Narratives. 
The entries are arranged by country, with concise and useful annotations. In addition, an appendix lists the publications the compiler has found especially useful or memorable, a boon to students or to the general reader. This is an exemplary bibliography.-MC.

\section{The Palestine Question in Maps 1878-}

2002. Jerusalem: PASSIA, Palestinian Academic Society for the Study of International Affairs, 2002. 165p. \$25 (ISBN 9950-305-02-00). LC 2003347032.

When Yassir Arafat negotiated the Oslo Peace Accords, he did not have in his possession detailed maps of the occupied territories. He certainly did not have anything close to the collection of geographic and demographic maps put together by Palestinian Academic Society for the Study of International Affairs, Jerusalem (PASSIA).

Founded in March 1987 by Dr. Mahdi Abdul Hadi with the help of a group of Palestinian academics and intellectuals in Jerusalem, PASSIA is a nonprofit Palestinian institution that seeks to present the question of Palestine in its national, Arab, and international contexts through academic research, dialogue, and publication. (See www.passia.org.)

The Palestine Question in Maps is a unique publication. Divided into five chapters, the book follows a chronological path to the modern Palestinian history, including political and military milestones, the various conflict resolution proposals, the intrinsic importance of Jerusalem, the core demographic, water, illegal settlements, refugee issues, and more. It contains first-time published documents. The more than fifty maps are accompanied by explanatory text, and both maps and text are referenced. The book also features a handy list of abbreviations, a short time line from 1915 (Hussein-McMahon cor- respondence begins) to 2001 (Taba talks fail), a six-page glossary, a bibliography useful as a research stepping stone, and an index.

Today, both researchers and interested readers will find this publication an important resource to understand the geographic, political, and military aspects of the Palestine Question. This publication is highly recommended for all library reference collections.-F.H.D.

\section{Gender Studies}

Men and Masculinities: A Social, Cultural, and Historical Encyclopedia. Ed. Michael Kimmel and Amy Aronson. 2 vols. illus. Santa Barbara, Calif.: ABCCLIO, 2004. \$255 (ISBN 1-57607-774-8). LC 2003-20729.

Men and Masculinities: A Social, Cultural, and Historical Encyclopedia provides an introduction to a relatively new field of gender studies that seeks to better understand the influence of gender on the lives of men. Inspired by the success and theoretical insights achieved in recent decades by women's studies, researchers in this new field are guided by two fundamental assumptions: gender influences men as profoundly as it does women, and concepts of masculinity have always varied widely according to historical period, culture, and social status.

Men and Masculinities consists of more than 450 articles on topics in the sciences, social sciences, and humanities. The articles, which typically range in length from one to four pages, are accessible, informative, and supported by up-to-date bibliographies. That is what one would expect from a work involving editors and many contributors with distinguished research and publishing records in the field of gender studies.

As a reference work, however, Men and Masculinities has important shortcomings. Although not indicated in the title, this 
encyclopedia concentrates almost exclusively on American social, cultural, and historical topics. Thus, readers will find an entry for Pee-wee Herman, but not Homer, whose epic poems profoundly influenced Western concepts of masculinity. (Despite the brooding image of the Roman emperor Caracalla dominating its front cover, this encyclopedia actually devotes little attention to Greek and Roman antiquity.) Other important historical topics are also largely overlooked. In the case of twentieth-century history, for instance, there is no entry for fascism; the single reference to that term in the index directs the reader to an article about Dirty Harry.

Surprisingly, given the international and comparative interests of much academic research today, Men and Masculinities similarly neglects non-Western subjects. There is no entry for Islam (strictly speaking, no longer a non-Western topic), a complex subject accorded only passing mention in an article on religion. G.I. Joe merits an article, but not Mohandas Gandhi. Demographic trends in China and India, two societies that now have alarming disparities between their male and female populations, pass unmentioned.

Even if Men and Masculinities is treated as an encyclopedia devoted primarily to American gender studies, the editors' choice of topics often seems arbitrary. To cite just a few examples: there are articles about blues, jazz, and rap, but not about country music, opera, or "glam rock." Jack Kerouac and Stephen King are accorded entries, but not Alfred Kinsey or John Fitzgerald Kennedy.

Readers interested in learning more about current research trends and theoretical perspectives in an important new field of gender studies will unquestionably benefit from browsing through Men and Masculinities. However, those seeking a comprehensive reference tool to assist their research or to systematically introduce them to the central concerns of this field will find this encyclopedia less useful.-J.L.

\section{Encyclopedia of Lesbian, Gay, Bisexual, and Transgender History in America.} Ed. Marc Stein. New York: Scribners, 2004. 3 vols. illus. \$380 (ISBN 0-68431261-1). LC 2003-017434.

Although this encyclopedia covers all aspects of American lesbian, gay, bisexual, and transgender history, it is especially useful for its focus on legal history. The encyclopedia begins with a 24-page chronology that, for the sixteenth through eighteenth centuries, is mostly a listing of legal cases and laws, with references to pertinent articles in the body of the encyclopedia.

The body of the encyclopedia includes more than 500 articles ranging from a single page (shorter biographical entries) to eight pages (the discussion of feminism) with most entries about three to four pages long. Signed entries include cross-references to other articles and very good bibliographies. There are entries for people; political movements, organizations and events; culture and the arts; academic disciplines and fields of inquiry; identities, communities, and cultures; geographies; law and public policy; economics and labor; sex and sexuality; religion and spirituality; language, symbols, and concepts; and social issues.

The contributors include many noted scholars and theorists. To name a few, Patrick Califia wrote the entries on androgyny, sadomasochism, sex acts, sex clubs, and suicide; William Eskridge wrote the entries on crime and criminalization, federal law and policy, immigration, asylum, and deportation law and policy; and Vern Bullough wrote entries on Edward I. Prime-Stevenson, sexually transmitted diseases, and situational homosexuality. 
The third volume concludes with an appendix listing archives and manuscript repositories of LGBT material in the U.S. and Canada, a systematic outline of the contents, a directory of contributors, and an excellent index. This encyclopedia is recommended for all libraries supporting research in lesbian, gay, bisexual, and transgender history.-S.W.

\section{Gates, Gary J., and Jason Ost. The Gay and} Lesbian Atlas. Washington, D.C.: Urban Institute Pr., 2004. 232p. illus. $\$ 49.50$ (ISBN 0-87766-721-7). LC 2004-002065. Based entirely on the 2000 census, this useful atlas has sections for states and cities providing maps showing the concentration of same-sex unmarried partner households by tract or county and tables illustrating age, race, and the presence of children. Comparative statistics show same-sex partners in the context of the entire state or city population. In addition to the state and city maps, six preliminary chapters address a variety of topics with additional tables and charts: Why Study Gay and Lesbian Location Patterns, Data and Methods, Estimating the Size of the Gay and Lesbian Population, Where do Gay and Lesbian Couples Live, Comparing Location Patterns across Different Couple Types, and Other Demographic Characteristics. This is a well-designed atlas and recommended for libraries of all sizes. - S.W.

\section{Business}

Brown, Robert, J. D., and Alan S. Gutterman. A Short Course in International Business Plans: Charting a Strategy for Success in Global Commerce (Short course in international Trade Series). Novato: World Trade Pr., 2003. 186p. $\$ 24.95$ (ISBN 1-885073-62-3). LCCN 2003-042258.

This is a "practical guide to the research, development and writing of an interna- tional business plan" (Intro.). The authors make two assumptions (1) that the reader has decided to go global and (2) that a specific market of best opportunity has already been chosen.

The first fourteen chapters address the basics of a plan, and then there are individual treatments of the nine sections of the plan, including human resources, marketing, finance, products and services, and management and organizational structure.

Sample plans are given in succeeding chapters covering software, technology manufacturing, and goods and services retailing companies. Samples of a nondisclosure agreement and financial statements are included. A glossary of standard business terms (e.g., "barriers to entry," "market life cycle") is appended.

Recommended for academic libraries supporting entrepreneurial programs and for public libraries with medium-to-large business collections. - J.L.C.

DealScan [electronic resource]. New York: Loan Pricing Corporation (http:// www.loanpricing.com). Subscription price varies.

DealScan provides detailed terms and conditions on more than 139,000 loan and high-yield bond transactions worldwide back to 1988, selected coverage back to 1981; approximately 200 to 250 transactions are added to the database every week. DealScan also contains access to the Gold Sheets, a news, data, and analytic source for the global loan market.

The search interface for DealScan has recently been upgraded and now has more functionality. Users can search by SIC code, by borrower, or by deal information. Results can be sorted by date, purpose, and industry and deal amount and then printed or downloaded to Excel 
This database is useful to track deals over time or gain a historical perspective on a company or market trends. Universities with an MBA program with a finance concentration would benefit most from this resource. - K.D.

\section{New Editions and Supplements}

The Dictionary of National Biography (AH226) and its supplements have been completely revised and retitled the Oxford Dictionary of National Biography (New York: Oxford UP, 2004. 61v. \$13,000). Unlike the American National Biography (AH62), the revision of the Dictionary of American Biography, no one was dropped from the earlier British version, though, of course, many people were added-some 12,000 in fact. All of the entries were revised or completely rewritten, and the new edition also includes some 10,000 illustrations chosen from the National Portrait Gallery and other collections.

An online version is also available, which includes the entries from the original Dictionary of National Biography. It is quite easy to navigate, though the approach seems a bit breezy for such a scholarly endeavor. (A button called "Get a Life" pulls up entries at random.) The advanced search allows for more complex searches.

Other new editions with title changes include the Nowy Slownik Fundacji Kościuszkowskiej=New Kosciuszko Foundation Dictionary (New York: The Foundation, 2v. \$135), a bilingual Polish/English, English/Polish dictionary. It is a "completely new bilingual dictionary" (Pref.), rather than a revision of the 1959-1961 Kościuszko Foundation Dictionary (AC634). The New Harvard Guide to Women's Heath (Cambridge: Harvard UP, 2004. 688p. $\$ 55)$ is the second revised edition of the 1996 Harvard Guide to Women's Health. The second edition of the 1999 Encarta World English Dictionary was published as the Encarta Webster's Dictionary of the
English Language (New York: Bloomsbury, 2,166p. \$50) and has added some 11,000 new words and meanings. The Oxford Dictionary of Proverbs (New York: Oxford Univ. Pr., 2003. 375p. \$30) is the fourth edition of the Concise Oxford Dictionary of Proverbs ( $3^{\text {rd }}$. ed., 1995; $2^{\text {nd }}$ ed. 1992; $1^{\text {st }}$ ed. 1983). American Foreign Relations Since 1600: A Guide to the Literature (Santa Barbara: ABC-CLIO, 2003. 2 vols. \$280.) is the second edition of the monumental 1983 Guide to American Foreign Relations Since 1700 (DB15).

New editions without title changes include the Oxford Companion to American Theatre (New York: Oxford Univ. Pr., 2004. 681p. \$75; $2^{\text {nd }}$ ed. 1992; $1^{\text {st }}$ ed. 1984), revised by Thomas Hishak. Entries have been updated and new thematic essays, for instance, AIDS in the American theater, have been added. Charles Cutter's Judaica Reference Sources: A Selected Annotated Bibliographic Guide ( $3^{\text {rd }}$ rev. and expanded ed. Westport, Conn.: Libraries Unlimited, 2004. 365p. \$50; $2^{\text {nd }}$ ed. 1993; $1^{\text {st }}$ ed. Jewish Reference Sources, 1982) now lists more than 1,000 sources, including selected Web sites, in several languages, emphasizing works published since 1970.

Paul Dickson's War Slang: American Fighting Words and Phrases Since the Civil War $\left(2^{\text {nd }}\right.$ ed. Washington, D.C.: Brassey's, 2004. 428p. \$24.95; $1^{\text {st }}$ ed. 1994) now includes terms from the first Iraq war. Another way to keep up to date with war words is the third edition of Richard Bowyer's Dictionary of Military Terms (London: Bloomsbury, 2004. 265p. \$17; $2^{\text {nd }}$ ed. 2002). The second edition of Reference Sources in History: An Introductory Guide (Santa Barbara: ABC-CLIO, 2004. 334p. $\$ 85 ; 1^{\text {st }}$ ed. 1990. DA2) now includes many more online sources, but its emphasis on English language and recently published material limits its scholarly use.

In the field of literature, The American College: An Annotated Bibliography (Lan- 
ham, Md.: Scarecrow, 2004. 405p. \$65; $1^{\text {st }}$ ed. 1981) describes 648 novels set in American colleges and universities that were written from 1828 to 2002; it is indexed by author, title, institution, and academic discipline. The second edition of Aphra Behn: An Annotated Bibliography of Primary and Secondary Sources (Aldershot, Eng.: Ashgate, 2004. 711p. \$99.95; $1^{\text {st }}$ ed. Garland, 1986) now lists works about her published through the year 2002 and includes online sources. The second edition of the Columbia Granger's Index to Poetry in Collected and Selected Works (New York: Columbia, 2004. 1847p. \$225; $1^{\text {st }}$ ed. 1996) now indexes some 65,000 poems in 315 works, with expanded coverage of more recent British and American writers.

Supplements and continuations include Wolfgang Behn's Concise Biographical Companion to Index Islamicus, published as the Bio-bibliographical Supplement to Index Islamicus, 1665-1980; vol.1. The Biographi- cal Companion will be in three volumes; volumes $1(\mathrm{~A}-\mathrm{G})$ and $3(\mathrm{~N}-\mathrm{Z})$ have been published (Leiden: Brill, 2004. \$199 each); volume 2 will be published in early 2006 . The work contains biographical information on the tens of thousands of authors of articles listed in the Index Islamicus (BC499), a who's who of Islamic scholars.

Supplement 1, containing some 300 new articles, of the Dictionary of the Middle Ages (DA148) was published in 2004. Volume 6, covering the years 1999-2000, of Twentieth-Century Short Story Explication (BE264) appeared in 2004. The 1997-1999 supplement to Black African Literature in English was published in 2003. On the Trail of the Buffalo Soldier II adds 2,000 new and nearly 1,000 revised biographies of black soldiers serving in the U.S. armed forces from 1866-1917. It also includes a revised and updated bibliography and an index to names, places, and institutions mentioned in both volumes. $-\mathrm{MC}$. 